\title{
Landslide damage assessment using the Support Analysis Framework (SAF): the 2009 landsliding event in Calabria (Italy)
}

\author{
O. Petrucci, A. A. Pasqua, and G. Gullà \\ CNR-IRPI, U.O.S. of Cosenza, Via Cavour, 4/6, 87030, Rende (Cosenza), Italy \\ Received: 12 February - Revised: 1 April 2010 - Accepted: 24 April 2010 - Published: 30 June 2010
}

\begin{abstract}
In this paper, a simplified methodological approach is used to assess damage indices related to landslide phenomena that occurred in Calabria (Italy) between November 2008 and January 2009. This approach, which was designed for and applied to single landslides, uses the Support Analysis Framework (SAF), a procedure containing the elements that can be damaged by a landslide grouped in categories. In this paper, we test wide-ranging use of the SAF on a number of landslides, assessing landslide damage on a municipal scale to get a final estimate of the amount of damage caused by all of the landslides that occurred in a selected municipality.

Data regarding the damage caused by landslides were gathered from the press. Daily newspapers were systematically collected and elaborated to assess direct, indirect and intangible damage caused during the abovementioned period by a rainfall-triggered landsliding event. In the paper, regional- and provincial-scale results are described, and the methodological approach is briefly described.

The application of the proposed methodological approach to the 2009 landsliding event shows that the results can be used to summarise landslide damage from a complex event in order to better plan an intervention strategy at a regional, provincial or municipal scale.

The availability of newspaper data during the event and the speed of the proposed approach allow for rapid location of the damaged sectors during the event, which will continuously upgrade the regional damage framework. This can all be done almost in "real time".
\end{abstract}

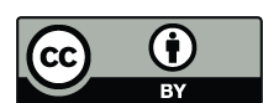

Correspondence to: O. Petrucci (o.petrucci@irpi.cnr.it)
For regional agencies, this framework can be a starting point to both manage the emergency and to acquire and interpret data giving a more detailed damage distribution so that a response can be organised. Moreover, based on the damage assessment, a characterisation of the landsliding event can also be carried out and used to describe the damage scenario occurring after each type of event.

\section{Introduction}

Calabria $\left(15230 \mathrm{~km}^{2}\right)$, the southernmost Italian peninsular region, is made up of allochthonous crystalline rocks (Palaeozoic to Jurassic in age) that were stacked over carbonate units during the middle Miocene. Neogene flysh fills the tectonic depressions. The mean altitude of the region is $418 \mathrm{~m}$ a.s.l. and the maximum elevation is $2266 \mathrm{~m}$ a.s.l.

The region is divided into five provinces made up of 409 municipalities. Ninety percent of territory is in relief and $10 \%$ consists of coastal and fluvial plains.

Weathering and degradation caused by tectonic stresses and climatic conditions deteriorate the outcropping rocks, widely predisposing slopes to instability (Gullà et al., 2006; Borrelli et al., 2007). The climate is Mediterranean, with dry summers and wet winters; the mean annual rainfall is $1151 \mathrm{~mm}$. During the winter season, rainfall often reaches high values on either a daily or a monthly basis.

Intense and/or prolonged rainfall can trigger landslides and floods occurring simultaneously across wide areas, making it difficult to both manage emergency actions and to finally recover from the damage. In previous works, these rainfall/damaging events have been known as Damaging Hydro-geological events (DHEs) (Petrucci and Polemio, 2008; Petrucci et al., 2008). 


\section{2009-Landsliding Event (LE)}

Between November 2008 and January 2009, intense and prolonged rainfall triggered one of the most severe DHE that has occurred in Calabria in recent years (Gullà et al., 2009). Landslides and floods in 234 of Calabria's municipalities (57\% of the total) caused severe damage all around the region. Two people were killed by a landslide while they were driving on the regional highway. The national government declared a state of emergency as the entire regional road network was affected by widespread landslide damage and several people were forced to temporarily leave the houses that were threatened by landslides.

Defining Landsliding Event (LE) the simultaneous activation of numerous landslides in a given time period, in this paper, we analyse damage caused by the 2009 LE. Landslide data were obtained by systematically consulting 93 editions of the daily newspaper "La Gazzetta del Sud" (from 1 November 2008 to 1 February 2009). In order to assess the landslide damage, the collected data were elaborated using a methodological approach proposed by Petrucci and Gullà (2009a, b).

\section{Assessment of landslide damage indices}

An analysis of historical data describing the damage caused by mass movements in Calabria allowed the creation of the Support Analysis Framework (SAF), a procedure that converts damage descriptions into numerical indices expressing damage (Petrucci and Gullà, 2009, 2010). The SAF can be used either to assess damage indices of mass movements that have already occurred or the potential outcomes of dormant phenomena re-activations. It is based on the effects on damaged elements and it is independent of both physical and geometric phenomenon characteristics.

In the SAF, damage is divided into direct, indirect, and intangible damage.

Direct damage includes all physical impacts on six types of elements: buildings, roads, railways, productive activities, network services, and people. It can be assumed as the product of two quantities: a) the relative value of each damaged element $(1,0.75,0.50$ or 0.25$)$, which is arbitrarily set based on both the cost of the element and the restoration cost, and b) the level of loss (complete loss: 1; high loss: 0.75; medium loss: 0.5 ; low loss: 0.25 ).

Six sections of the SAF, which concern the abovementioned types of elements, assess a numerical value that is normalised to the maximum possible damage that can be obtained for the analysed section. The result is a series of six damage indices (one for each section) quantitatively expressing the damage to each type of damaged element. Starting from a minimum level of severity, we have: D1= low damage (0.25); D2=medium damage $(0.5<\mathrm{D} 2 \leq 0.25)$; D3=high damage $(0.75<\mathrm{D} 3 \leq 0.5)$; and $\mathrm{D} 4=$ =very high dam- age $(1<\mathrm{D} 4 \leq 0.75)$. D represents the damage that affected a section (i.e. the section containing the different types of buildings) due to a landslide.

Indirect damage is expressed by 13 actions aiming to restore pre-landslide conditions and re-establish public safety conditions. For the first group of actions, damage levels are assigned according to an estimate of what amount of money is necessary to perform the action (i.e., to construct retaining walls or remove unstable rock blocks) divided in four ranges $(D 1=$ less than $10000 €, D 2=$ between $10000 €$ and $50000 €, \mathrm{D} 3=$ between 50 and $10000 €$, and D4=more than $100000 €)$. For the second group of actions, damage levels are set based on the number of people involved divided into four ranges [i.e. arrangement of foodstuffs and basic necessities for displaced people could be set for: a) less than 10 people (D1), b) for a number of people between 10 and 30 (D2), c) between 30 and 60 (D3), or d) for more than 60 people (D4)].

Intangible damage takes into account psychological consequences due to the landslide. Also in this case, damage levels are set according to the number of people involved.

Finally, the Direct Damage Index is assessed by summing the values obtained from all the direct damage sections of the SAF; Indirect Damage Index is assessed by summing the values obtained from the indirect damage sections, and Intangible Damage Index is the sum of the results of Intangible Damage sections. Finally, a summarizing Total Damage Index can be assessed by summing Direct, Indirect and Intangible damage indices.

\section{Data analysis and results}

Data collected from newspapers concerning landslides triggered in Calabria by the 2008-2009 rainfall seasons were elaborated using the SAF, and the results were analysed at both a provincial and regional scale.

Table 1 lists Calabria provinces (Cosenza, Catanzaro, Crotone, Vibo Valentia and Reggio Calabria) from north to south, their area and population density. For each province, the number of municipalities damaged by the 2009 event is shown (either as a number or as a percentage of the number of municipalities of the province). Then, in order to summarise the overall impact of landslides on each province, we reported the total number of municipalities affected for each province and divided them into four classes based on the value of total landslide damage suffered (D1, D2, D3 and D4).

In Fig. 1, for each province, a map of the damaged municipalities is shown. In the first histograms to the left of each provincial map, the damaged municipalities have been classified according to the type of damage (direct, indirect and intangible), and in the second ones according to the type of damaged elements. In both the histograms, $N$ is the number of municipalities damaged by landslides during the event, 
Table 1. Main characteristics of Calabria provinces (Area, Population, and Number of municipalities of the province). The impact of the 2009 landsliding event for each province is expressed by the number of municipalities damaged (either as the amount or percentage of the municipalities of the province that were damaged) and the total number of municipalities affected, which were divided into four classes according to the total cost of the landslide damage (D1, D2, D3 and D4). On the right, the map shows the Calabria region.

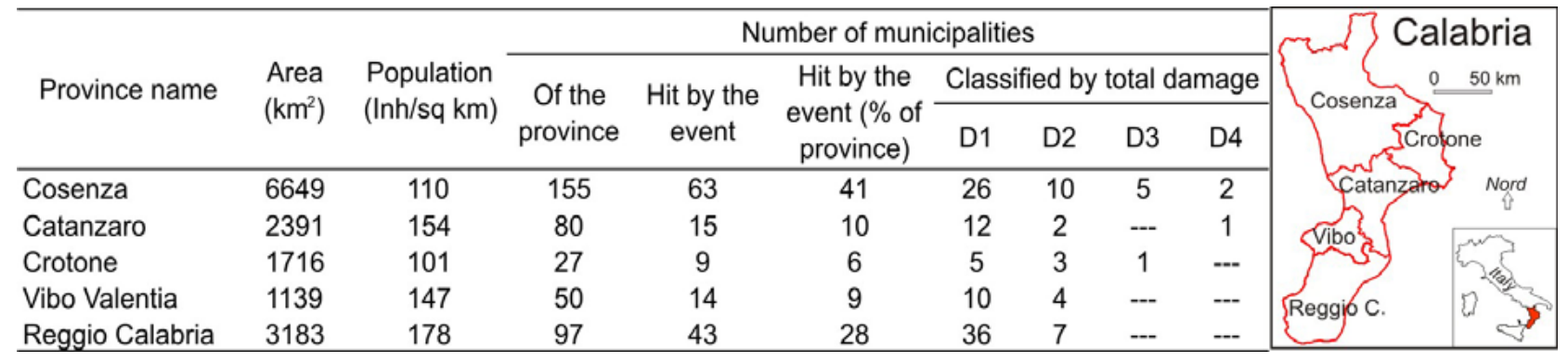

and the colours of the bars are set according to the damage levels, as is shown in the legend.

By analysing the available data, we can highlight some major points:

1. Direct damage affects a great number of municipalities found in all the provinces, but a high percentage of these municipalities only suffer slight damage (green bars in the Damage type histograms).

2. Indirect damage is mainly tied to the costs of repairing the roads, and secondly to lodging for temporarily displaced people who were living in houses that were threatened by the landslides.

3. The high values of intangible damage are probably related to the type of information source (newspapers). In fact, reporters often emphasise the aspects concerning intangible damage in order to catch the reader's attention.

4. Cosenza and Reggio were the most widely damaged provinces; Cosenza was the most severely hit.

5. In all of the provinces, the roads and buildings sustained the most damage of all the elements.

6. The overall severity of the event is tied mainly to a wide area of low damage rather than high damage concentrated on small sectors, as seen during similar previous events in Calabria.

\section{Conclusions}

We used the SAF (Support Analysis Framework) to preliminarily assess the landslide damage that occurred in Calabria between November 2008 and January 2009, after a period of intense and prolonged rainfall. In the present work, the approach used to assess damage caused by a single landslide (Petrucci and Gullà, 2009, 2010) is applied to several landslides occurred during a regional landsliding event.
Newspaper data were systematically elaborated to create a framework of landslide damage at both a regional and provincial scale.

This approach can be used to preliminarily assess damage after events triggering several landslides over wide areas. The availability of newspaper data during the event allows for rapid localisation of damaged sectors almost in "real time".

For regional agencies, this framework can be a starting point to both manage emergency phases and acquire data that can be used to obtain a more detailed damage distribution, upon which relief efforts can be based.

Finally, a damage assessment carried out using the proposed approach could allow us to the characterisation of landsliding events based upon its impact on the community.

One of the future targets of the research will be the comparative analysis of newspaper dataset and data coming from official surveys, carried out by regional offices supported by CNR-IRPI and University of Calabria researchers in order to allocate funds for damage repairing: at present, only an incomplete framework is available, and it mainly concerns the cases in which the most severe damage occurred.

Newspaper data, used in this work, are non technical data, but they are available during the event and can supply a framework of the event: clearly this framework can be considered as a preliminary investigation to be analysed in depth by mean of field surveys.

Edited by: M. C. Llasat

Reviewed by: one anonymous referee 

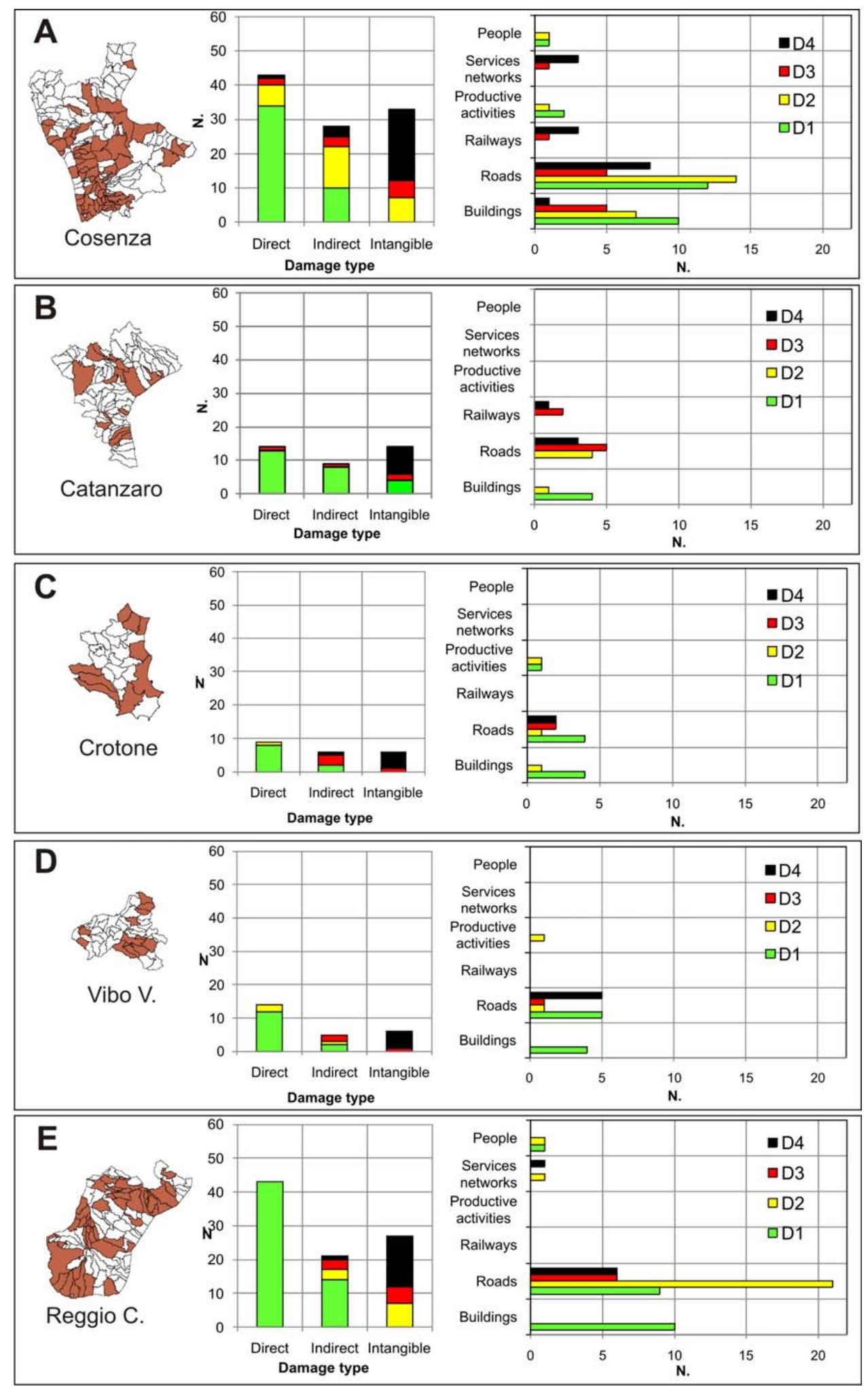

Fig. 1. Impact of the 2009 landsliding event on the provinces of Calabria. For each province, the map shows the location of municipalities damaged during the event. In the first histograms on the left of each provincial map, the damaged municipalities were classified according to the type of damage suffered (direct, indirect and intangible), and, in the second ones, according to the type of damaged elements. $N$ is the number of municipalities damaged by landslides during the event, and the colours of the bars are set according to the damage levels, as is shown in the legend. 


\section{References}

Borrelli, L., Greco, R., and Gullà, G.: Weathering grade of rock masses as a predisposing factor to slope instabilities: Reconnaissance and control procedures, Geomorphology, 87, 158-175, 2007.

Gullà, G., Antronico, L., Borrelli, L., Caloiero, T., Coscarelli, R., Iovine, G., Nicoletti, P. G., Pasqua, A. A., Petrucci, O., and Terranova, O.: Indicazioni conoscitive e metodologiche connesse all'evento di dissesto idrogeologico dell' autunno-inverno 2008 2009 in Calabria. Geologi Calabria (Rivista dell'Ordine dei Geologi della Calabria), Anno 10, N. 1, 4-21, 2009.

Gullà, G., Mandaglio, M. C., and Moraci, N.: Effect of weathering on the compressibility and shear strength of a natural clay, Can. Geotech. J., 43(6), 618-625, 2006.
Petrucci, O. and Gullà, G.: A Support Analysis Framework for mass movement damage assessment: applications to case studies in Calabria (Italy), Nat. Hazards Earth Syst. Sci., 9, 315-326, doi:10.5194/nhess-9-315-2009, 2009.

Petrucci, O. and Gullà, G.: A simplified method for landslide damage scenario assessment based on historical data, Nat. Hazards, 52(3), 539-560, 2010.

Petrucci, O. and Polemio, M.: The role of meteorological and climatic conditions in the occurrence of damaging hydro-geologic events in Southern Italy, Nat. Hazards Earth Syst. Sci., 9, 105118, doi:10.5194/nhess-9-105-2009, 2009.

Petrucci, O., Polemio, M., and Pasqua, A. A.: Analysis of Damaging Hydrogeological Events: the case of the Calabria Region (Southern Italy), Environ. Manag., 25, 483-495, 2008. 